\title{
ENRAIZAMENTO DE ESTACAS JUVENIS DO MARMELEIRO 'JAPONÊS' ESTRATIFICADAS A FRIO E TRATADAS COM AIB
}

\author{
Rooting of juvenile cutting of 'Japonês' quince of cold stratificated and dipped in IBA
}

\author{
Rafael Pio ${ }^{1}$, Fernando Antônio Campo Dall'Orto², Ângelo Albérico Alvarenga ${ }^{3}$, \\ Enilson Abrahão ${ }^{4}$, Guilherme Signorini ${ }^{5}$, Edvan Alves Chagas ${ }^{1}$
}

\begin{abstract}
RESUMO
Realizou-se o presente trabalho com o objetivo de verificar a estratificação a frio associada à aplicação de AIB, no enraizamento de estacas juvenis do marmeleiro 'Japonês'. Foram coletadas estacas lenhosas do marmeleiro 'Japonês' (Chaenomelis sinensis L.) em mudas de um ano de idade e altura de $130 \mathrm{~cm}$, padronizadas com $25 \mathrm{~cm}$ de comprimento, sem folhas e com diâmetro de $0,8 \mathrm{~cm}$. Uma parte das estacas foi estratifica a frio por 30 dias (estacas embrulhadas em jornal umedecido e protegidas com saco plástico à temperatura de $4^{\circ} \mathrm{C}$ ) e outra parte colocada diretamente para enraizar, em telado constituído por sombrite $50 \%$ de luminosidade. As estacas, antes de serem enterradas a $2 / 3$ de seu comprimento em leito de areia umedecido, foram tratadas com diferentes concentrações de $\operatorname{AIB}\left(0,1000,2000\right.$ e $\left.3000 \mathrm{mg} . \mathrm{L}^{-1}\right)$, por 10 segundos. Após 90 dias avaliou-se a porcentagem de estacas enraizadas, com calos e brotadas, bem como o número médio de brotos, folhas e raízes por estaca. Conclui-se que as estacas juvenis possuem alto potencial de propagação via estaquia, devendo-se não estratificar as estacas a frio e tratá-las com $1000 \mathrm{mg} . \mathrm{L}^{-1}$ de AIB.
\end{abstract}

Termos para indexação: Chaenomelis sinensis L., propagação, estaquia e estratificação.

\begin{abstract}
The objective of this work was to verify the cold stratification associated with the application of IBA, in rooting of juvenile cutting of the 'Japonês' quince. Woody cutting of the 'Japonês' quince (Chaenomelis sinensis L.) were collected in seedlings with one year old and $130 \mathrm{~cm}$ of height, standardized with $25 \mathrm{~cm}$ of length, without leaves and diameter of $0.8 \mathrm{~cm}$. A part of the cutting was cold stratificated for 30 days (cuttings in humidified newspaper and protected with plastic sack at $4^{\circ} \mathrm{C}$ ) and other part placed directly to rooting, in nursery conditions with $50 \%$ of brightness. The cuttings were treated with different concentrations of IBA $(0,1000,2000$ and $3000 \mathrm{mg} . \mathrm{L}^{-1}$ ), for 10 seconds. After 90 days, the percentage of cuttings rooted was evaluated the percentage of that one with callous and sprouted, as vellas, the mean number of sprouts, leaves and roots by cuttings. Cuttings is not cold stratification and treat with $1000 \mathrm{mg} \cdot \mathrm{L}^{-1}$ of IBA.
\end{abstract}

Index terms: Chaenomelis sinensis L., propagation, cutting and stratification.

(Recebido para publicação em 4 de novembro de 2005 e aprovado em 29 de junho de 2006)

\section{INTRODUÇÃO}

A marmelocultura na década de 30 exerceu importante papel no desenvolvimento sócio-econômico da região Sul do Estado de Minas Gerais, principalmente nos municípios de Delfim Moreira, Cristina, Maria da Fé, Virgínia e Marmelópolis, destacando-se por ser a principal região produtora do País e possuir dezenas de indústrias processadoras de marmelos (HIROTO, 2002). O Estado de Minas Gerais, embora ainda seja o maior produtor de marmelos do País, apresenta sérias limitações ao cultivo, destacando-se a falta de incentivos, problemas fitossanitários e desinteresse do mercado consumidor (ABRAHÃO et al., 1996). Pode-se dizer que a cultura do marmeleiro se encontra, hoje, em fase de transição, existindo uma forte tendência em sair do ponto de estagnação, com a implantação de novos e mais produtivos marmeleirais. Esse fato pode ser observado pelo interesse em novos plantios de marmelos em outras regiões, como é o caso dos municípios de Luziânia e Morrinhos, em Goiás e em Capelinha, no Norte de Minas Gerais. No Sul de Minas, também se observa uma tendência de ampliação de cultivos e recuperação de pomares existentes.

Apesar dos frutos de marmeleiros da espécie Cydonia oblonga Mill. possuírem sementes viáveis, estas são em pequena quantidade (menos de dez em cada fruto). O uso do marmeleiro 'Japonês' (Chaenomeles sinensis L.) via seminífera, como porta-enxerto para as outras espécies

${ }^{1}$ Engenheiro Agrônomo, D.Sc., Professor Adjunto da Universidade Estadual do Oeste do Paraná/UNIOESTE - Rua Pernambuco n 1777 - Cx. P. 1008 - Centro - 85.960-000 - Marechal Cândido Rondon, PR - rafaelpio@ hotmail.com

Engenheiro Agrônomo, M.Sc., Pesquisador Científico Centro APTA Frutas - Instituto Agronômico/IAC - Jundiaí, SP - facampo@iac.sp.gov.br ${ }^{3}$ Engenheiro Agrônomo, D.Sc., Pesquisador EPAMIG-CTSM - Lavras, MG - angelo@epamig.ufla.br

${ }^{4}$ Engenheiro Agrônomo, M.Sc., Pesquisador EMBRAPA/EPAMIG-CTSM - Lavras, MG - enilson@epamig.ufla.br

${ }^{5}$ Graduando em Agronomia - Universidade de São Paulo, Escola Superior de Agricultura "Luiz de Queiroz" - Piracicaba, SP - Estagiário Centro APTA Frutas - Instituto Agronômico/IAC - Judiai, SP - signorin@esalq.usp.br 
e cultivares de marmelos, tem se mostrado viável, principalmente pelo elevado número de sementes por fruto (aproximadamente 150), poder germinativo, uniformidade e afinidade entre as principais cultivares de marmelos utilizadas nas regiões mineiras e paulistas (ABRAHÃO et al., 1991).

O inconveniente da reprodução sexual é a obtenção de plântulas desuniformes, o que não é desejado no estabelecimento de plantios comerciais, devido à segregação gênica. Sendo assim, a estaquia ou enxertia vem a ser a alternativa de propagação mais viável para os marmeleiros, mantendo as características genéticas das plantas matrizes, uniformidade, porte reduzido e precocidade de produção (FACHINELLO et al., 1995; HARTMANN et al., 2002).

Alguns trabalhos relacionados com o enraizamento de estacas do marmeleiro 'Japonês' foram desenvolvidos atualmente, porém os resultados não são satisfatórios, devendo assim ser mais bem estudado.

Pio et al. (2004a), trabalhando com o enraizamento de estacas lenhosas de diversas cultivares de marmeleiro, obtiveram apenas $12,5 \%$ de estacas enraizadas dessa cultivar de marmeleiro, sem qualquer tratamento na estaca. Porém, quando as estacas dos referidos marmeleiros foram estratificadas em areia por 45 dias e posteriormente tratadas com AIB, os resultados foram ainda menores (2,5\% de estacas enraizadas do marmeleiro 'Japonês') (PIO et al., 2004b). Assim, outras alternativas para a propagação desses marmeleiros por estaquia devem ser testadas.

Um método utilizado para aumentar o potencial de enraizamento das estacas lenhosas é a estratificação das estacas em leito de areia umedecido ou em baixa temperatura (temperaturas inferiores a $7,2^{\circ} \mathrm{C}$ ), técnica que possui como finalidade ausentar o material propagativo de luz ou então suprir a necessidade de frio, com o intuito de superar a endodormência das gemas e aumentar o enraizamento das estacas (BIASI, 1996).

Associada a estratificação das estacas, a aplicação de fitoreguladores, no caso, auxinas, permitem auxiliar no aumento da porcentagem de enraizamento. Dentre as auxinas sintéticas, o ácido indolbutírico (AIB) é o fitoregulador mais comumente utilizado na indução do enraizamento adventício, por se tratar de uma substância fotoestável, de ação localizada e menos sensível à degradação biológica, em comparação às demais auxinas sintéticas, podendo, em muitas espécies de difícil enraizamento, viabilizar a produção de mudas por meio da estaquia (FACHINELLO et al., 1995).
Buscou-se com o presente trabalho estudar técnicas auxiliares como a estratificação a frio associada à aplicação de AIB, no enraizamento de estacas juvenis do marmeleiro 'Japonês'.

\section{MATERIAL E MÉTODOS}

Foram coletadas estacas lenhosas do marmeleiro 'Japonês', em mudas de um ano de idade e altura de 130 $\mathrm{cm}$, oriundas de propagação seminífera (material juvenil), padronizadas com $25 \mathrm{~cm}$ de comprimento, sem folhas e diâmetro de $0,8 \mathrm{~cm}$, aproveitando o descarte de mudas utilizadas em enxertia. Uma parte das estacas foi estratifica a frio por 30 dias (estacas embrulhadas em jornal umedecido e protegidas com saco plástico à temperatura de $4^{\circ} \mathrm{C}$ ) e outra parte colocada diretamente para enraizar, em telado constituído por sombrite $50 \%$ de luminosidade. As estacas antes de serem enterradas a $2 / 3$ de seu comprimento em leito de areia umedecido, foram tratadas com diferentes concentrações de AIB (0, 1000, 2000 e $\left.3000 \mathrm{mg} . \mathrm{L}^{-1}\right)$, por 10 segundos.

O delineamento utilizado foi o inteiramente casualizado, em esquema fatorial $2 \times 4$ (primeiro fator: estacas estratificadas ou não; segundo fator: concentrações de AIB), com quatro repetições e dez estacas por parcela. As avaliações ocorreram após 90 dias do estaqueamento, coletando os seguintes dados biométricos: porcentagem de estacas enraizadas, com calos e brotadas, além do número médio de brotos, folhas e raízes por estaca.

Os dados foram submetidos à análise de variância e as médias ao teste Scott-Knott ao nível de 5\% de probabilidade (GOMES, 2000). As análises foram realizadas pelo programa computacional Sistema para Análise de Variância - SISVAR (FERREIRA, 2000).

\section{RESULTADOS E DISCUSSÃO}

Através da análise estatística, constatou-se que houve interação entre a estratificação e as concentrações de AIB para as variáveis porcentagem de estacas enraizadas, com calos e brotadas e diferença estatística entre o número médio de brotos e folhas apenas entre estacas estratificadas ou não.

Estacas colocadas diretamente para enraizar e submetidas à aplicação de $1000 \mathrm{mg} . \mathrm{L}^{-1}$ de AIB promoveram $45 \%$ de enraizamento. Quando as estacas foram estratificadas a frio e posteriormente tratadas com o fitoregulador, houve decréscimo linear para o enraizamento, obtendo-se $43 \%$ de estacas enraizadas sem a utilização do AIB (Figura 1-A). O mesmo ocorreu para a porcentagem

Ciênc. agrotec., Lavras, v. 31, n. 1, p. 71-74, jan./fev., 2007 
de estacas com calos e brotadas, obtendo-se melhores resultados para ambas as variáveis em estacas estratificadas a frio e não tratadas com AIB $(95,84 \%$ de estacas calejadas e $97,87 \%$ de estaca brotadas), ocorrendo queda em concentrações crescentes do fitorregulador (Figuras 1-B e 1-C).
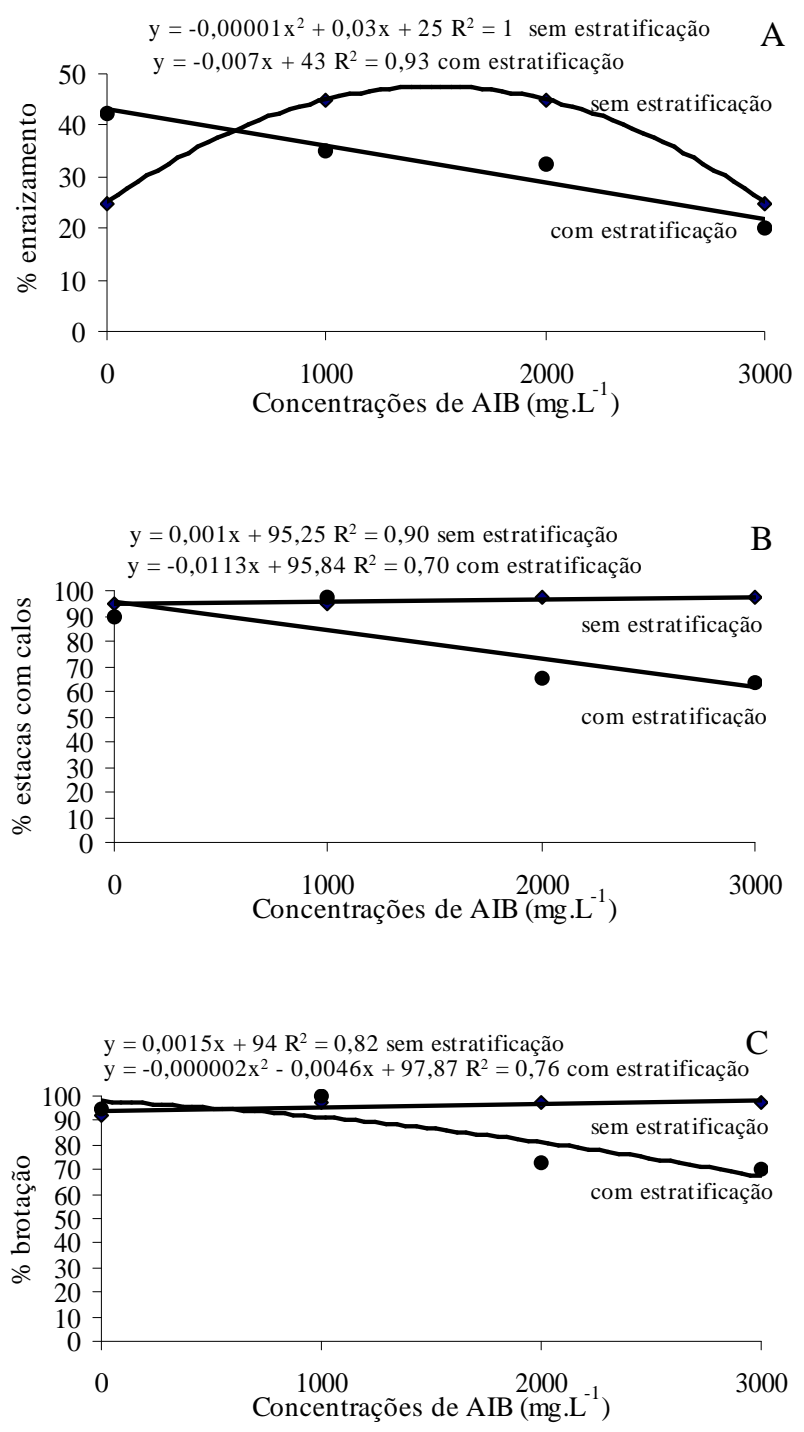

FIGURA 1 - Porcentagem de estacas enraizadas (A), porcentagem de estacas com calos (B) e porcentagem de estacas brotadas (C) do marmeleiro 'Japonês' submetidas à estratificação ou não em baixa temperatura e tratadas com diferentes concentrações de AIB. Jundiaí-SP, Centro APTA Frutas/IAC, 2005.
Obteve-se assim melhoria do enraizamento das estacas do marmeleiro 'Japonês' em aproximadamente $32 \%$, em comparação aos dados encontrados na literatura (PIO et al., 2004a), tomando como base as estacas não estratificadas a frio e tratadas com 1000 mg. $L^{-1}$ de AIB. Vale ressaltar que, apesar de apresentar aproximadamente a mesma porcentagem de enraizamento das estacas estratificadas e não tratadas com AIB, esta é estatisticamente superior, mas economicamente menos viável por se utilizar o fitoregulador.

Uma das razões para esse aumento pode estar associada à utilização de material propagativo juvenil, que possui maior potencial de enraizamento, em comparação a porções oriundas de tecidos adultos (HARTMANN et al., 2002). Outra razão para esse sucesso pode estar associada à estratificação das estacas. O ácido indolacético (AIA) é a auxina de ocorrência natural nas plantas, responsável pela emissão natural de raízes nas estacas. O AIA-oxidase é um sistema enzimático, que ocorre em várias plantas, catalisando a degradação do AIA, formando novos compostos e inativando a iniciação radicular, que seria promovida pela auxina (WAREING \& PHILLIPS, 1981). A inibição do AIA-oxidase, provocada pela presença de certos compostos fenólicos, como o ácido clorogênico e cafeico, favorece o enraizamento de estacas (BIASI, 1996). O estiolamento das estacas provoca alterações no conteúdo de compostos fenólicos, que desempenham um importante papel no metabolismo das auxinas, atuando como cofatores de auxinas e inibindo a AIA-oxidase (MAYNARD \& BASSUK, 1988). A estratificação promove a iniciação de primórdios radiculares na base da estaca e impede o desenvolvimento precoce das brotações, as quais teriam efeito prejudicial, exaurindo suas reservas e provocando desidratação pela transpiração das brotações (HARTMANN et al., 2002).

Pode-se reforçar essa hipótese por meio dos resultados obtidos para o número médio de brotos e folhas, nas quais a estratificação a frio promoveu os melhores resultados, apesar de não ter ocorrido diferença entre estacas estratificadas ou não para o número médio de raízes por estaca (Tabela 1). Quanto ao número médio de raízes por estacas, os dados obtidos, tanto para as estacas não estratificadas quanto para as estratificadas, vem a confirmar com a literatura que o marmeleiro emiti poucas raízes na base das estacas (PIO et al., 2004a). 
TABELA 1 - Número médio de brotos, folhas e raízes por estaca do marmeleiro 'Japonês' submetidas a estratificação ou não em baixa temperatura. Jundiaí-SP, Centro APTA Frutas/IAC, 2005.

\begin{tabular}{lllll}
\hline & \multicolumn{4}{c}{ Variáveis analisadas* } \\
\cline { 2 - 5 } & $\begin{array}{l}\mathbf{N}^{\mathbf{0}} \text { médio } \\
\text { de brotos }\end{array}$ & $\begin{array}{l}\mathbf{N}^{\mathbf{0}} \text { médio } \\
\text { de folhas }\end{array}$ & $\begin{array}{l}\mathbf{N}^{\mathbf{0}} \text { médio } \\
\text { raízes/estaca }\end{array}$ \\
\cline { 2 - 5 } Sem estratificação & $2,22 \mathrm{~b}$ & 9,69 & $\mathrm{~b}$ & 3,71 a \\
Com estratificação & $2,65 \mathrm{a}$ & $15,93 \mathrm{a}$ & 4,10 a \\
cv $(\%)$ & 16,51 & 24,45 & 27,04 \\
\hline
\end{tabular}

* Médias seguidas pela mesma letra em minúsculo na coluna não diferem estatisticamente entre si pelo teste Tukey ao nível de 5\% de probabilidade.

\section{CONCLUSÕES}

Pode-se concluir que as estacas juvenis possuem alto potencial de propagação via estaquia, devendo-se não estratificar as estacas a frio e tratá-las com $1000 \mathrm{mg} . \mathrm{L}^{-1}$ de AIB

\section{REFERÊNCIAS BIBLIOGRÁFICAS}

ABRAHÃO, E.; ALVARENGA, A. A.; SOUZA, M. de. Marmeleiro (Chaenomelis sinensis) cv. Japonês: portaenxerto para marmeleiros, pereiras e nespereiras. Revista Brasileira de Fruticultura, Cruz das Almas, v. 13, n. 2, p. 181-182, out. 1991.

ABRAHÃO, E.; SOUZA, M. de; ALVARENGA, A. A. A cultura do marmeleiro em Minas Gerais. Belo Horizonte: EPAMIG, 1996. 23 p. (Boletim técnico, 47).

BIASI, L. A. Emprego do estiolamento na propagação de plantas. Ciência Rural, Santa Maria, v. 26, n. 2, p. 309-315, maio/ago. 1996.

FACHINELLO, J. C.; HOFFMANN, A.; NACHTIGAL, J. C.; KERSTEN, E.; FORTES, G. R. de L. Propagação de plantas frutíferas de clima temperado. 2. ed. Pelotas: UFPel, 1995. $178 \mathrm{p}$.
FERREIRA, D. F. Análise estatística por meio do SISVAR (Sistema para Análise de Variância) para Windows versão 4.0. In: REUNIÃO ANUAL DA REGIÃO BRASILEIRA DA SOCIEDADE INTERNACIONAL DE BIOMETRIA, 45., 2000, São Carlos. Anais... São Carlos: UFSCar, 2000. p. 255-258.

GOMES, F. P. Curso de estatística experimental. 14. ed. Piracicaba: USP/ESALQ, 2000. 477 p.

HARTMANN, H. T.; KESTER, D. E.; DAVIES JUNIOR, F. T.; GENEVE, R. L. Plant propagation: principles and practices. 7. ed. New Jersey: Prentice Hall, 2002. 880 p.

HIROTO, C. H. Enraizamento de estacas dos marmeleiros 'Japonês' e 'Portugal' em diferentes substratos e concentrações de ácido indolbutírico. 2002. 56 p. Dissertação (Mestrado em Agronomia) - Universidade Federal de Lavras, Lavras, 2002.

MAYNARD, B. K.; BASSUK, N. L. Estiolation and banding effect on adventitious root formation. In: DAVIS, T. D.; HAISSIG, B. E.; SANKLHA, N. (Eds.). Adventitious root formation in cuttings. Portland: Discorides, 1988. p. 29-46.

PIO, R.; ARAÚJO, J. P. C. de; SCARPARE FILHO, J. A.; MOURÃO FILHO, F. de A. A.; ALVARENGA, A. A.; ABRAHÃO, E. Potencial de propagação de cultivares de marmeleiro por estaquia. Revista Brasileira de Fruticultura, Jaboticabal, v. 26, n. 2, p. 287-289, ago. 2004a.

PIO, R.; RAMOS, J. D.; CHALFUN, N. N. J.; GONTIJO, T. C. A.; CARRIJO, E. P.; VISIOLI, E. L.; TOMASETTO, F. Enraizamento de estacas lenhosas de marmeleiros 'Portugal' e 'Japonês' estratificadas em areia e tratadas com AIB. Revista Brasileira de Agrociência, Pelotas, v. 10, n. 3, p. 367-370, jul./set. 2004b.

WAREING, F. P.; PHILLIPS, I. D. J. Growth and differentiation in plants. Oxford: Pergamen, 1981. 343 p. 